\title{
АНАЛИЗ АССОЦИАЦИИ ПОЛИМОРФНЫХ ВАРИАНТОВ Т>C RS767455 ГЕНА TNFRSF1A И T>G RS1061622 ГЕНА TNFRSF1B C РАЗВИТИЕМ НЕАЛКОГОЛЬНОГО СТЕАТОГЕПАТИТА
}

\author{
Л. В. Топчиева ${ }^{1 凶}$, И. В. Курбатова , О. П. Дуданова², А. А. Шиповская² \\ "Институт биологии, Федеральный исследовательский центр "Карельский научный центр Российской академии наук", Петрозаводск \\ Медицинский институт, Петрозаводский государственный университет, Петрозаводск
}

\begin{abstract}
В этиологии и патогенезе неалкогольной жировой болезни печени (НАЖБП) важны особенности питания, малоподвижный образ жизни и наследственность. Предполагают, что полиморфные варианты генов, кодирующих рецепторы к провоспалительному цитокину фактору некроза опухоли альфа (TNFa) (TNFRI и TNFRII), влияют на предрасположенность людей к развитию НАЖБП. Однако сведения о связи данного заболевания с носительством полиморфных вариантов генов TNFRI и TNFRII почти отсутствуют в литературе. Целью исследования было изучить связь полиморфных вариантов генов TNFRSF1A (T>C rs767455) и TNFRSF1B (T>G rs1061622) с развитием одной из форм НАЖБП неалкогольного стеатогепатита (НАСГ) и их влияние на биохимические показатели крови. Методом ПЦР-ПДРФ генотипировали ДНК, выделенную из венозной крови 151 здорового донора и 242 пациентов с диагнозом НАСГ. Содержание TNFa оценивали с помощью иммуносерментного анализа (ИФА). По результатам, связь полиморфного маркера Т>C rs767455 гена TNFRSF1A с развитием НАСГ у жителей Карелии отсутствует. Обнаружена ассоциация с НАСГ полиморфного варианта T>G rs1061622 гена TNFRSF1B. У носителей аллеля G повышен риск развития данного заболевания ОШ = 4,83 (95\% ДИ: 2,72-8,57). Влияние генотипа по T>G rs1061622 маркеру гена TNFRSF1B на содержание TNFa и активность аланинаминотрансферазы (АлАТ), аспартатаминотрансферазы (АсАТ) и щелочной фоосфатазы (ЩФ) не выявлено. Сделано заключение, что полиморфный вариант T>G rs1061622 гена TNFRSF1B может быть вовлечен в предрасположенность населения Карелии к НАСГ.
\end{abstract}

Ключевые слова: неалкогольный стеатогепатит, наследственность, фактор некроза опухоли альфа, рецепторы к фактору некроза опухоли альфа, mbTNFRI, sTNFR, ген TNFRSF1A, ген TNFRSF1B, полиморсизм генов, аланинаминотрасфераза, аспартатаминотрансфераза

Финансирование: финансирование осуществлялось из федерального бюджета на выполнение государственного задания КарНЦ РАН (тема № 02212017-0049) на оборудовании Центра коллективного пользования ФИЦ «Карельский научный центр Российской академии наук», при поддержке стипендии Президента РФ для молодых ученых и аспирантов, осуществляющих перспективные научные исследования и разработки по приоритетным направлениям модернизации российской экономики на 2015-2017 гг.; в рамках «Программы стратегического развития Петрозаводского государственного университета в 2013-2017 г.», (НИОКР № 115070110006, ИКРБС № 216022450003), проекта «Разработка технологии скрининговой диагностики неалкогольной жировой болезни печени у лиц с избыточным весом и метаболическим синдромом» № 9173ГУ/2015 от 15.12.2015 г. программы «У.М.Н.И.К.».

Для корреспонденции: Топчиева Людмила Владимировна

ул. Пушкинская, д. 11, г. Петрозаводск, 198910; Topchieva67@mail.ru

Статья получена: 31.10.2017 Статья принята к печати: 02.03.2018

DOI: $10.24075 /$ vrgmu.2018.008

\section{ANALYSIS OF THE ASSOCIATION BETWEEN THE RS767455 T>C TNFRSF1A AND RS1061622 T>G TNFRSF1B POLYMORPHISMS AND NONALCOHOLIC STEATOHEPATITIS}

\author{
Topchieva LV1®, Kurbatova IV11, Dudanova OP², Shipovskaya AA²
}

'Institute of Biology, Karelian Research Center of RAS, Petrozavodsk, Republic of Karelia

${ }^{2}$ Institute of Medicine, Petrozavodsk State University, Petrozavodsk, Republic of Karelia

Poor diet, sedentary behavior and genetic background are major factors contributing to the etiology and pathogenesis of non-alcoholic fatty liver disease (NAFLD). It is hypothesized that polymorphisms of the TNFRI and TNFRIl genes coding for the receptors that bind the proinflammatory cytokine tumor necrosis factor alpha (TNFa) can be implicated in the susceptibility to NAFLD, but not much data is available in the literature. In the present work we aimed to investigate a possible association between the rs767455 T>C TNFRSF1A and rs1061622 T>G TNFRSF1B polymorphisms and one of NAFLD forms, nonalcoholic steatohepatitis (NASH), and to assess their effect on blood biochemistry. Samples of DNA isolated from the venous blood of 151 healthy donors and 242 patients with NASH were genotyped using PCR-RFLP. TNFa concentrations were measured by ELISA. We have not found any association between the rs767455 T>C TNFRSF1A polymorphism and the development of NASH in the residents of Karelia. However, we have discovered an association between NASH and the T>G TNFRSF1B rs1061622 polymorphism. Carriers of the $\mathrm{G}$ allele have a higher risk of developing NASH (OR = 4.83; 95\% Cl: 2.72-8.57). The rs1061622 T>G genotype of the TNFRSF1B gene appears to have no effect on TNFa concentrations and the activity of alanine aminotransferase (ALT), aspartate aminotransferase (AST) and alkaline phosphatase (ALP). Our findings suggest a possible association between the rs1061622 T>G TNFRSF1B polymorphism and a risk of developing NASH in the residents of Karelia.

Keywords: non-alcoholic steatohepatitis, tumor necrosis factor alpha, tumor necrosis factor alpha receptors, mbTNFRI, STNFR, TNFRSF1A gene, TNFRSF1B gene, gene polymorphism, alanine aminotransferase, aspartate aminotransferase

Funding: this study was part of the public contract 0221-2017-0049 and was carried out using the equipment of the shared facility Complex Basic and Applied Research of Living Systems in the Arctic of the Institute of Biology, Karelian Research Center. The work was also sponsored by a scholarship of the President of the Russian Federation for young scientists and graduate students engaged in advanced research and development in priority areas of modernization of the Russian economy in 2015-2017 years. The authors also received support from Petrozavodsk State University as part of the efforts for its strategic development in 20132017 (R\&D 115070110006, Information reference map 216022450003, registered February 24, 2016) under the project for the Development of Technologies for Diagnostic Screening for Nonalcoholic Fatty Liver Disease in Overweight Patients and Patients with Metabolic Syndrome (ID 9173GU/2015 dated December 15, 2015) of the UMNIK program.

$\triangle$ Correspondence should be addressed: Ludmila Topchieva

ul. Pushkinskaya 11, Petrozavodsk, 198910; topchieva67@mail.ru

Received: 31.10.2017 Accepted: 02.03.2018

DOI: $10.24075 /$ brsmu.2018.008 
Развитие и прогрессирование неалкогольной жировой болезни печени (НАЖБП), одной из форм которой является неалкогольный стеатогепатит (НАСГ), сопровождается повышением в плазме крови и печени провоспалительных цитокинов, в частности фактора некроза опухоли альфа (TNFa) $[1,2]$. Повышенный уровень TNFa способствует воспалению печени, отложению в ней липидов и их перекисному окислению, активации клеток Купфера и апоптозу гепатоцитов, формированию инсулинорезистентности [3]. Снижение концентрации TNFa в плазме крови приводит к улучшению показателей функционального состояния печени [4, 5].

Белки семейства TNF проявляют свои биологические эффекты посредством взаимодействия с рецепторами суперсемейства TNFR[6]. Рецепторы к TNFa (mbTNFR) представлены двумя типами трансмембранных белков (mbTNFRI, mbTNFRII), отличающимися друг от друга наличием или отсутствием во внутриклеточной области домена смерти, активация которого приводит к запуску сигнальных путей апоптоза или некроптоза [7]. Помимо мембраносвязанных, существуют и растворимые рецепторы TNFa (sTNFR), образующиеся в результате отщепления внеклеточной части белка от mbTNFR с помощью металлопротеиназ семейства ADAM [8]. STNFR связываются с TNFa и выступают как антагонисты mbTNFR, препятствуя запуску TNFa-сигнальных путей. В небольшой концентрации растворимые рецепторы TNFa обнаружены в сыворотке и моче здоровых людей. Уровень циркулирующих TNFR увеличивается при хроническом вирусном гепатите [9], циррозе печени [10], НАЖБП [11, 12], что указывает на развитие воспалительного процесса в организме при этих заболеваниях и активацию Т-клеточного иммунного ответа, в частности активацию CD8 ${ }^{+}$Т-клеток, экспрессирующих металлопротеиназу ADAM-17 [8]. Предполагается, что уровень и соотношение растворимых и мембраносвязанных рецепторов TNFa играет существенную роль не только в индукции процессов гибели гепатоцитов и повреждении печени, но и в процессах регенерации и поддержании гомеостаза этого органа $[13,14,15,16]$. Вероятно, соотношение между растворимыми и мембраносвязанными формами TNFRI и TNFRII во многом определяет силу иммунного ответа и воспалительных реакций в организме. Оказывается, мутации в генах TNFRSF1A и TNFRSF1B влияют, соответственно, на содержание sTNFRI и sTNFRII в плазме крови и на количество mbTNFRI и mbTNFRII на поверхности клеток врожденного иммунитета [17]. В связи с этим можно предположить, что полиморфные варианты генов рецепторов TNFa могут вносить значительный вклад в этиологию и патогенез заболеваний печени, в частности НАСГ. В настоящее время предпринимаются попытки установить связь полиморфизма генов, кодирующих TNFR, с развитием НАЖБП. Однако такого рода данные еще малочисленны и касаются связи полиморфизма генов TNFRSF1A и TNFRSF1B с развитием биллиарного цирроза, алкогольной болезни печени и гепатоцеллюлярной карциномы $[18,19,20]$. Сведения об ассоциации полиморфных вариантов генов рецепторов TNFa с развитием НАЖБП практически отсутствуют в литературе. В связи с этим, целью исследования явилось изучение влияния полиморфных вариантов генов TNFRSF1A и TNFRSF1B на развитие НАСГ у жителей Карелии.

\section{ПАЦИЕНТЫ И МЕТОДЫ ИССЛЕДОВАНИЯ}

Материал для исследования получен при содействии кафедры пропедевтики внутренних болезней и гигиены Ме- дицинского института ПетрГУ и клинико-диагностической лаборатории НУЗ ОКБ на ст. Петрозаводск ОАО «РЖД». В исследовании использовали 242 образца венозной крови пациентов с НАСГ (110 мужчин и 132 женщин) и 151 образец крови здоровых доноров (64 мужчин и 87 женщин). Доноры, включенные в дальнейшем в контрольную группу (группу здоровых доноров), были также обследованы врачами НУЗ ОКБ на ст. Петрозаводск ОАО «РЖД" в ходе диспансеризации. Все испытуемые были разделены на клинические группы: контрольная группа - здоровые доноры, без клинических проявлений НАЖБП (возраст 48,04 $\pm 2,26$ года); группа пациентов с диагнозом НАСГ (возраст 50,14 \pm 2,46 года). Возраст представлен в виде среднего значения \pm ошибка среднего. Возраст доноров двух групп исследования значимо не различался $(U=132,5 ; p=0,637)$. Общими критериями включения пациентов в обе наблюдаемые группы, явились: лица обоих полов, давшие информированное согласие на проведение исследования, проживающие в Республике Карелия, с отсутствием вирусной этиологии хронического гепатита на основании отрицательных результатов исследования HBsAg вируса гепатита B и антител к вирусу гепатита C, a также с отсутствием алкогольной, лекарственной и аутоиммунной этиологии болезни печени на основании анамнестических, клинических, лабораторных данных. Критериями включения для больных НАСГ, кроме указанных, стали: впервые установленный диагноз НАЖБП слабой и умеренной активности до терапии (форма НАЖБП НАСГ). Общими критериями исключения пациентов для обеих изучаемых групп явились: перенесенные в последний месяц инфекционно-воспалительные заболевания, беременность и лактация, курение, сахарный диабет, индекс массы тела $\geq 30$ кг/M², прием лекарственных, в том числе гепатотропных препаратов. Диагноз НАЖБП устанавливался на основании традиционных клинических, лабораторных, инструментальных и гистологических данных. Оценивались следующие лабораторные показатели крови: активность АлАТ и АсАТ, активность ЩФ (данные показатели определяли в автоматическом режиме на биохимическом анализаторе «RandomAccessF-15», «BioSystems", Испания). При ультразвуковом исследовании у всех больных выявлялось увеличение размеров печени и усиление эхогенности паренхимы органа. У части больных диагноз НАСГ подтвержден при гистологическом исследовании биоптатов печени.

Забор венозной крови для исследования в объеме 10 мл проводили до назначения лекарственных, в том числе гепатотропных, препаратов с использованием вакуумных пробирок с антикоагулянтом (ЭДТА). 250 мкл использовали для выделения ДНК. Часть венозной крови использовали для получения плазмы. Плазму крови объемом 200 мкл использовали для определения концентрации TNFa. Остальной объем крови был использован для определения биохимических показателей крови.

На проведение исследования получено согласие Комитета по медицинской этике Минздравсоцразвития PK и ПетрГУ (протокол № 39 от 15 ноября 2017 г).

У части доноров, выбранных случайным образом, определяли содержание TNFa в плазме крови иммуноферментным методом (ИФА) с использованием набора «Human TNFo Platinum ELISA» («eBioscience», Австрия). Исследовали 30 образцов плазмы крови здоровых доноров (возраст 49,11 \pm 1,81 года) и 60 образцов плазмы крови больных НАСГ (возраст 49,95 \pm 2,74 года) с равным количеством мужчин и женщин в группах. Возраст лиц в исследуемых 
группах достоверно не различался $(U=181,5 ; p=0,535)$. Оптическую плотность раствора измеряли на микропланшетном фотометре Sunrise («Теcan», Австрия) при длине волны 450 нм и референсной длине волны 620 нм.

ДНК выделяли из периферической крови на микроколонках с помощью набора «К-Сорб» (Синтол, Россия). Качество и количество ДНК определяли спектрофотометрически на приборе «SmartSpec» («Bio-Rad», CШA).

Для амплификации части гена TNFRSF1A, включающую позицию 339 (rs767455), использовали праймеры: прямой 5'agtggctgaggttaggac3' и обратный 5'ctatgcccgagtctcaac3', описанные в работе [21]. Для амплификации области гена TNFRSF1B, включающей позицию 587 (rs1061622), использовали праймеры: прямой 5'gcacacatcgtcactctc3' и обратный 5'aaggagtgaatgaatgagac3', описанные в работе [21]. Полимеразную цепную реакцию (ПЦР) проводили в амплификаторе iCycler iQ5 («Bio-Rad», CШA), используя реакционную смесь («Евроген», Россия). ПЦР-продукты, содержащие rs767455, обрабатывали эндонуклеазой рестрикции Bse1 I (1 е.а.) («Сибэнзим», Россия) в течение 3 ч при $65^{\circ} \mathrm{C}$. ПЦР-продукты, содержащие rs1061622, обрабатывали эндонуклеазой рестрикции Fatl (1 е.а.) ("Сибэнзим", Россия) в течение 14 при $55^{\circ} \mathrm{C}$. После рестрикции фрагменты ДНК разделяли в 1,5\%-м агарозном геле, используя трис-ацетатный бусрер.

Статистическую обработку данных проводили в программе Statgraphics 2.1. Достоверность различий частот аллелей и генотипов в группах оценивали с помощью критерия $\chi^{2}$, биохимических показателей между группами - c помощью непараметрического критерия U УилкоксонаМанна-Уитни. Непараметрический критерий для анализа был использован в связи с несоответствием распределений показателей в группах нормальному. Для оценки влияния генотипов на биохимические показатели использовали дисперсионный анализ Краскела-Уоллиса. Для оценки риска развития НАСГ рассчитывали отношение шансов (ОШ) с 95\%-м доверительным интервалом (95\% ДИ) [22]. Различия считали достоверными при значении $\mathrm{p}<0,05$.

\section{РЕЗУЛЬТАТЫ ИССЛЕДОВАНИЯ}

На рис. 1 и 2 представлены электрофореграммы продуктов рестрикции ПЦР-фррагметов, содержащих rs767455 и rs1061622.

Проанализированы частоты аллелей и генотипов по полиморфному маркеру T>C rs767455 гена TNFRSF1A в контрольной группе и группе пациентов с НАСГ.

Проводили тест на соответствие распределения равновесию Харди-Вайнберга. В контрольной группе и группе НАСГ обнаружено отклонение частот аллелей и генотипов от уравнения Харди-Вайнберга $\left(\chi^{2}=8,25\right.$ (df $\left.=2, p<0,05\right)$, $\chi^{2}=21,64(\mathrm{df}=2, \mathrm{p}<0,05)$ соответственно).

Как видно из табл. 1, частоты аллелей и генотипов по полиморфному маркеру T>C (rs767455) гена TNFRSF1A не различались в группах здоровых доноров и больных НАСГ.

Проанализированы частоты аллелей и генотипов по 587T>G полиморфному маркеру гена TNFRSF1B в контрольной группе и группе пациентов с НАСГ.

В исследованных группах не обнаружено отклонения частот аллелей и генотипов от уравнения Харди-Вайнберга $\left(\chi^{2}=0,30(d f=2, p>0,05), \chi^{2}=4,16(d f=2, p>0,05)\right.$ соответственно в группе здоровых доноров и группе больНЫх НАСГ).

Как видно из табл. 2, распределение частот аллелей и генотипов полиморфного маркера 587T>G гена TNFRSF1B различается в группах здоровых и больных НАСГ людей. Встречаемость аллеля $\mathrm{G}$ в группе лиц с диагнозом НАСГ значительно выше, чем в контрольной группе. У носителей аллеля $\mathrm{G}$ повышен риск развития данного заболевания (ОШ = 4,83 (95\% ДИ: 2,72-8,57)).

Оценивали влияние rs1061622 гена TNFRSF1B на некоторые функциональные биохимические показатели состояния печени и содержание TNFa в плазме крови (табл. 3). Достоверные различия изучаемых показателей у носителей разных генотипов в двух сравниваемых группах не обнаружены. Не обнаружено влияние генотипа по указанному маркеру на биохимические показатели крови как в группе здоровых доноров, так и в группе пациентов с НАCГ $(p>0,05)$

\section{ОБСУЖДЕНИЕ РЕЗУЛЬТАТОВ}

Мы проанализировали связь полиморфных вариантов rs767455 гена TNFRSF1A и rs1061622 гена TNFRSF1B с развитием НАСГ. Указанные полиморфные варианты по данным литературы ассоциированы с рядом воспалительных заболеваний и изменением уровня TNFa в плазме крови [23]. Полиморфный вариант rs767455 представляет собой синонимическую мутацию, расположенную в позиции 36 первого экзона гена TNFRSF1A. Известно, что синонимические мутации могут влиять на правильность и эффективность сплайсинга мРНК, изменять ее структуру и влиять на фолдинг белков [24]. Показано, что замена аденина на гуанин в 36-й позиции гена TNFRSF1A приводит к изменению кодона CCA на CCG, что влияет на эффективность трансляции [25]. Кроме того, данная мутация в сочетании с другими мутациями (гаплотип Т-А-Т по rs4149570-rs767455-rs1800692) в гене TNFRSF1A

$\mathrm{M}$

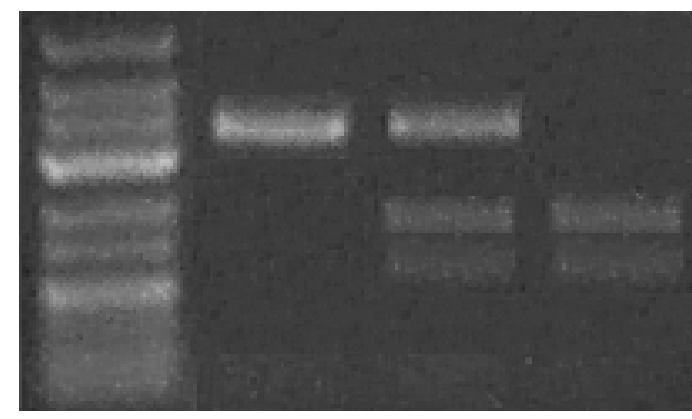

Рис. 1. Электрофореграмма продуктов рестрикции ПЦР-фрагметов, содержащих rs767455: M - Thermo Scientific GeneRuler Low range DNA Ladder, 1 - генотип СС (330 п.н.), 2 - генотип ТС (330, 184 и 146 п.н.), 3 — генотип П (184 и 146 п.н.)

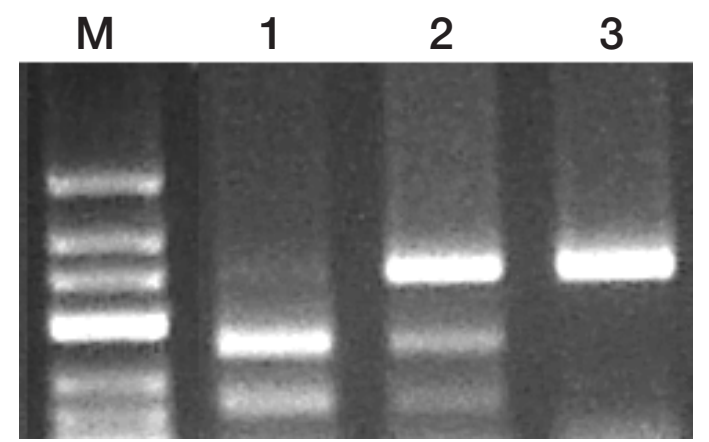

Рис. 2. Электросфореграмма продуктов рестрикции ПЦР-фрагметов, содержащих rs1061622: M - Thermo Scientific GeneRuler Low range DNA Ladder, 1 - генотип Tा (235 и 144 п.н.), 2 — генотип TG $(379,235$ и 144 п.н.), 3 - генотип GG (379 п.н.) 
Таблица 1. Распределение аллелей и генотипов по полиморфному маркеру T>C rs767455 гена TNFRSF1A в группе пациентов с НАCГ и в контрольной группе

\begin{tabular}{|c|c|c|c|}
\hline Аллели и генотипы & Контрольная группа $(\mathrm{n}=131)$ & Пациенты с НАСГ $(\mathrm{n}=242)$ & $229(0,47)$ \\
\hline $\mathrm{T}$ & $119(0,45)$ & $255(0,53)$ \\
\hline $\mathrm{C}$ & $143(0,55)$ & $72(0,30)$ & $0,24(\mathrm{df}=1, \mathrm{p}>0,05)$ \\
\hline $\mathrm{TT}$ & $35(0,26)$ & $85(0,35)$ \\
\hline TC & $48(0,37)$ & $85(0,35)$ & $0,61(\mathrm{df}=2, \mathrm{p}>0,05)$ \\
\hline CC & $48(0,37)$ & \\
\hline
\end{tabular}

Таблица 2. Распределение аллелей и генотипов по полиморфному маркеру T>G rs1061622 гена TNFRSF1B в группе пациентов с HACГ и в контрольной группе

\begin{tabular}{|c|c|c|c|}
\hline Аллели и генотипы & Контрольная группа ( $\mathrm{n}=151)$ & Пациенты с НАСГ (n = 133) & Критерий $\chi^{2}$ \\
\hline $\mathrm{T}$ & $206(0,68)$ & $116(0,44)$ & \multirow{2}{*}{$\begin{array}{c}16,60 \\
(d f=1, p<0,05)\end{array}$} \\
\hline G & $96(0,32)$ & $150(0,56)$ & \\
\hline$\pi T$ & $69(0,46)$ & $20(0,15)$ & \multirow{3}{*}{$\begin{array}{c}37,07 \\
(\mathrm{df}=2, \mathrm{p}<0,01)\end{array}$} \\
\hline TG & $68(0,45)$ & $77(0,58)$ & \\
\hline GG & $14(0,09)$ & $36(0,27)$ & \\
\hline
\end{tabular}

Таблица 3. Некоторые показатели крови носителей разных генотипов по полиморфному маркеру 587T>G (rs1061622) гена TNFRSF1B в группах здоровых доноров и пациентов с НАСГ

\begin{tabular}{|c|c|c|c|c|}
\hline \multirow{2}{*}{$\frac{\text { Показатель }}{\text { Генотип }}$} & \multicolumn{2}{|c|}{ Контроль } & \multicolumn{2}{|c|}{ НАСГ } \\
\hline & $\pi T(n=14)$ & $T G+G G(n=16)$ & $\pi(n=20)$ & $\mathrm{TG}+\mathrm{GG}(\mathrm{n}=40$ \\
\hline АЛАТ, Ед./Л & $\begin{array}{c}17,29 \pm 2,05 \\
(17,05)\end{array}$ & $\begin{array}{c}18,31 \pm 2,34 \\
(18,27)\end{array}$ & $\begin{array}{c}5936 \pm 8,53 \\
(45,90)\end{array}$ & $\begin{array}{c}65,56 \pm 8,68 \\
(48,30)\end{array}$ \\
\hline АСАТ, Ед./л & $\begin{array}{c}24,36 \pm 2,64 \\
(19,50)\end{array}$ & $\begin{array}{c}22,08 \pm 2,72 \\
(19,09)\end{array}$ & $\begin{array}{c}51,22 \pm 9,65 \\
(41,05)\end{array}$ & $\begin{array}{c}51,51 \pm 6,27 \\
(35,60)\end{array}$ \\
\hline ЩФ, Ед./л & $\begin{array}{c}118,42 \pm 10,82 \\
(117,46)\end{array}$ & $\begin{array}{c}123,51 \pm 17,14 \\
(125,48)\end{array}$ & $\begin{array}{c}218,00 \pm 18,70 \\
(210,00)\end{array}$ & $\begin{array}{c}214,26 \pm 11,28 \\
(197,00)\end{array}$ \\
\hline TNFa, пг/мл & $\begin{array}{c}5,53 \pm 1,38 \\
(4,69)\end{array}$ & $\begin{array}{c}4,82 \pm 0,39 \\
(5,08)\end{array}$ & $\begin{array}{c}6,09 \pm 0,43 \\
(5,83)\end{array}$ & $\begin{array}{c}6,36 \pm 0,27 \\
(6,27)\end{array}$ \\
\hline
\end{tabular}

Примечание: данные представлены в виде $\mathrm{M} \pm \mathrm{m}$ (Медиана).

способствует снижению пула мРНК без экзона 2 [26]. Нами не обнаружена ассоциация данного полиморфного маркера гена TNFRSF1A с развитием НАСГ среди обследованных лиц. Однако нами выявлена связь носительства аллеля G по T>G rs1061622 полиморфному маркеру гена TNFRSF1B с повышением риска развития НАСГ.

Полиморфный вариант rs1061622 гена TNFRSF1B представляет собой замену тимина на гуанин в позиции 587 экзона 6, которая приводит к замене аминокислотных остатков (метионин заменяется на аргинин) в позиции 196 трансмембранного домена белка, близко к сайту протеолитического расщепления металлопротеазами семейства ADAM. Указанная мутация влияет на процесс отщепления внеклеточного фрагмента трансмембранного белка и его выходу во внеклеточное пространство (эктодоменный шеддинг). Некоторые исследования показали, что у носителей генотипа TT (Met196) уровень sTNFRII ниже чем у лиц, имеющих Arg196-форму рецептора [27]. По данным других авторов, у носителей Т+ТG генотипов по данному полиморфному маркеру уровень STNFRII в плазме крови выше, чем у доноров с генотипом GG [28].

Таким образом, указанная мутация может способствовать изменению соотношения мембраносвязанных и растворимых TNFRII как в обычных физиологических условиях, так и при воспалении. Как уже отмечалось, у больных с различными заболеваниями печени наблюдается повышение содержания sTNFRI и STNFRII в плазме крови и печени. Причем уровень этих белков может позитивно корре- лировать с тяжестью заболевания [10, 12, 29, 30]. Однако физиологическая роль усиления эктодоменного шеддинга рецепторов TNFa при воспалении не совсем понятна. Так, увеличение содержания STNFRII и связанное с ним уменьшение количества mbTNFRII на поверхности клеток могут привести к активации сигнальных путей, опосредованных mbTNFRI и направленных на индукцию апотоза [7]. Помимо этого, растворимые формы TNFR могут функционировать в качестве физиологических аттенюаторов активности TNFa, конкурируя за лиганд с мембраносвязанными рецепторами. С другой стороны, растворимые рецепторы, вероятно, способны стабилизировать и сохранять циркулирующий растворимый TNFa и, таким образом, действовать как его агонисты [31].

Формы Met196 и Arg196 TNFRII различаются по своей способности опосредовать сигналинг TNF и активировать апоптоз или некроптоз. Так, в эпителиальных клетках линии HeLaS3, трансфицированных плазмидой pcDNA3.1, содержащей аллель Arg196 гена TNFRII, наблюдали снижение активности ядерного фактора кВ и рекрутирования TRAF2 после стимуляции клеток рекомбинантным TNFa [32]. Последующая активация сигнального пути TNFRI в этих клетках приводила к индукции апоптоза, тогда как в клетках, трансфицированных плазмидой с аллелем дикого типа Met196, выживаемость клеток была на более высоком уровне. Необходимо отметить, что НАСГ сопровождается активацией гибели гепатоцитов [33]. Можно предположить, что полиморфный вариант rs1061622 гена 
TNFRSF1B вносит свой вклад в формирование и прогрессирование НАСГ через индукцию сигнальных путей, определяющих гибель клеток печени.

Другой механизм вовлечения полиморфного варианта rs1061622 гена TNFRSF1B в этиологию и патогенез НАСГ может быть связан с его влиянием на уровень провоспалительных цитокинов [34]. Мы исследовали содержание TNFa в плазме крови носителей разных аллелей и генотипов по указанному полиморфному маркеру в группах здоровых и больных НАСГ людей. Однако достоверных различий в уровне этого цитокина в группах сравнения мы не выявили. Несмотря на это, мы не будем строго утверждать об отсутствии влияния полиморфного варианта rs1061622 гена TNFRSF1B на содержание TNFa, поскольку полученные результаты могут быть следствием как статистических флуктуаций из-за малочисленности выборки, по крайней мере, в группе здоровых доноров, так и влияния других факторов на этот показатель. Эти обстоятельства требуют дальнейшего изучения механизмов вовлечения указанного полиморфного маркера в этиологию и патогенез НАСГ.

\section{ВЫВОДЫ}

Не обнаружена связь носительства полиморфного варианта T>C rs767455 гена TNFRSF1A с развитием НАСГ у жителей Карелии. Выявлена ассоциация полиморфного варианта T>G rs1061622 гена TNFRSF1B с развитием НАСГ. Указанный полиморфный маркер может быть вовлечен в генетическую предрасположенность жителей Карелии к НАСГ.

\section{Литература}

1. Lebensztejn DM, Kowalczuk D, Tarasów E, Skiba E, Kaczmarski M. Tumor necrosis factor alpha and its soluble receptors in obese children with NAFLD. Adv Med Sci. 2010; 55 (1): 74-9. PubMed PMID: 20371430. DOI: 10.2478/v10039-0100008-5.

2. Bocsan IC, Milaciu MV, Pop RM, Vesa SC, Ciumarnean L, Matei DM et al. Cytokines genotype-phenotype correlation in nonalcoholic steatohepatitis. Oxid Med Cell Longev. 2017; 2017:4297206. Epub 2017 Aug 9. PubMed PMID: 28852433. DOI: 10.1155/2017/4297206.

3. Braunersreuther V, Viviani GL, Mach F, Montecucco F. Role of cytokines and chemokines in non-alcoholic fatty liver disease. World Journal of Gastroenterology. 2012; 18: 727-35. PubMed PMID: 22371632. DOI: 10.3748/wjg.v18.i8.727.

4. Lee Y-M, Sutedja DS, Wai C-T, Dan Y-Y, Aung M-O, Zhou L et al. A randomized controlled pilot study of Pentoxifylline in patients with non-alcoholic steatohepatitis (NASH). Hepatol Int. 2008; 2 (2): 196-201. PubMed PMID: 19669304. DOI: 10.1007/s12072008-9058-1.

5. Kakino S, Ohki T, Nakayama H, Yuan X, Otabe S, Hashinaga $T$ et al. Pivotal role of TNF- $\alpha$ in the development and progression of nonalcoholic fatty liver disease in a murine model. Horm Metab Res. 2017 Sep 18. [Epub ahead of print]. PubMed PMID: 28922680. DOI: 10.1055/s-0043-118666.

6. Locksley RM, Killeen N, Lenardo MJ. The TNF and TNF receptor superfamilies: integrating mammalian biology. Cell. 2001; 104: 487-501. PubMed PMID: 11239407.

7. Cabal-Hierro L, Lazo PS. Signal transduction by tumor necrosis factor receptors. Cellular Signalling. 2012; 24: 1297-1305. PubMed PMID: 22374304. DOI: 10.1016/j.cellsig.2012.02.006.

8. DeBerge MP, Ely KH, Wright PF, Thorp EB, Enelow RI. Shedding of TNF receptor 2 by effector CD8+ T cells by ADAM17 is important for regulating TNF- $\alpha$ availability during influenza infection. $J$ Leukoc Biol. 2015; 98: 423-34. PubMed PMID: 26019295. DOI: 10.1189/Jlb.3A0914-432RR.

9. Левитан Б. Н., Астахин А. В., Левитан Г. Б. Фактор некроза опухолей и его растворимые рецепторы ॥ типа при хронических гепатитах и циррозах печени. Экспериментальная и клиническая гастроэнтерология. 2017; 2: 62-6.

10. Lin SY, Wang YY, Sheu WH. Increased serum leptin concentration correlate with soluble tumour necrosis factor receptor levels in patients with cirrhosis. Clinical Endocrinol (Oxf). 2002; 57: 80511. PubMed PMID: 12460331.

11. Hui JM, Hodge A, Farrell GC, Kench JG, Kriketos A, George J. Beyond insulin resistance in NASH: TNF-alpha or adipo-nectin? Hepatology. 2004; 40: 46-54. PubMed PMID: 15239085.

12. Tokushige K, Takakura M, Tsuchiya-Matsushita N, Taniai M, Hashimoto E, Shiratori K. Influence of TNF gene polymorphisms in Japanese patients with NASH and simple steatosis. J Hepatol. 2007; 46: 1104-10. PubMed PMID: 17395331. DOI: 10.1016/j. jhep.2007.01.028.
13. Tarrats N, Moles A, Morales A, García-Ruiz C, FernándezCheca JC, Marí M. Critical role of tumor necrosis factor receptor 1 , but not 2, in hepaticstellate cell proliferation, extracellular matrix remodeling, and liver fibrogenesis. Hepatology. 2011; 54: 31927. PubMed PMID: 21523796. DOI: 10.1002/hep.24388.

14. Ijiri Y, Katoa R, Sadamatsua M, Takano M, Okadac Y, Tanaka K et al. Chronological changes in circulating levels of soluble tumor necrosis factor receptors 1 and 2 in rats with carbon tetrachlorideinduced liver injury. Toxicology. 2014; 316: 55-60. PubMed PMID: 24389507. DOI: 10.1016/j.tox.2013.12.004.

15. Sorg U, Behnke K, Degrandi D, Reich M, Keitel V, Herebian D et al. Cooperative role of lymphotoxin b receptor and tumor necrosis factor receptor p55 in murine liver regeneration. Journal of Hepatology. 2016; 64: 1108-17. PubMed PMID: 26708145. DOI: 10.1016/j.jhep.2015.12.006.

16. Lana JP, Martins LB, Oliveira MC, Menezes-Garcia Z, Yamada LT, Vieira $L Q$ et al. TNF and IL-18 cytokines may regulate liver fat storage under homeostasis conditions. Appl Physiol Nutr Metab. 2016; 41: 1295-1302. PubMed PMID: 27863204. DOI: 10.1139/ apnm-2016-0265.

17. Sennikov SV, Vasilyev FF, Lopatnikova JA, Shkaruba NS, Silkov AN. Polymorphisms in the tumor necrosis factor receptor genes affect the expression levels of membrane-bound type I and type II receptors. Mediators Inflamm. 2014; 2014:745909. Epub 2014 Mar 24. PubMed PMID: 24782596. DOI: 10.1155/2014/745909.

18. Wang J, Ni H, Chen L, Liu YX, Chen CB, Song WQ. Preparation and analysis of CSNP chip on hepatocellular carcinoma-related genes. Hepatobiliary Pancreat Dis Int. 2005; 4: 398-402. PubMed PMID: 16109524.

19. Machado MV, Martins A, Almeida R, Marques-Vidal $P$, Gonçalves MS, Camilo ME et al. Does the simultaneous tumor necrosis factor receptor 2, tumor necrosis factor promoter gene polymorphism represent a higher risk for alcoholic liver disease? Eur J Gastroenterol Hepatol. 2009; 21: 201-5. PubMed PMID: 19212208. DOI: 10.1097/MEG.0b013e32831016e0.

20. Liu X, Invernizzi P, Lu Y. Kosoy R, Lu Y, Bianchi I et al. Genomewide meta-analyses identify three loci associated with primary biliary cirrhosis. Nat Genet. 2010; 42: 658-60. PubMed PMID: 20639880. DOI: 10.1038/ng.627.

21. Xu F, Zhou G, Han S, Yuan W, Chen S, Fu Z et al. Association of TNF- $\alpha$, TNFRSF1A and TNFRSF1B gene polymorphisms with the risk of sporadic breast cancer in northeast Chinese Han women. PloS One. 2014; 9 (7): e101138. PubMed PMID: 25010932. DOI: 10.1371/journal.pone.0101138.

22. Флетчер Р. Клиническая эпидемиология. М.: Изд-во «Медиа-Сфрера»; 1998. 352 с.

23. Glossop JR, Dawes PT, Nixon NB, Mattey DL. Polymorphism in the tumor necrosis factor receptor II gene is associated with circulating levels of soluble tumor necrosis factor receptors in rheumatoid arthritis. Arthritis Research \& Therapy. 2005; 7: 1227- 
34. PubMed PMID: 16277675. DOI: 10.1186/ar1816.

24. Hunt R, Sauna ZE, Ambudkar SV, Gottesman MM, KimchiSarfaty C. Silent (synonymous) SNPs: should we care about them? Methods Mol Biol. 2009; 578: 23-39. PubMed PMID: 19768585. DOI: 10.1007/978-1-60327-411-1-2.

25. Matsukura H, Ikeda S, Yoshimura N, Takazoe M, Muramatsu M. Genetic polymorphisms of tumor necrosis factor receptor superfamily $1 \mathrm{~A}$ and $1 \mathrm{~B}$ affect responses to infliximab in Japanese patients with Crohn's disease. Aliment Pharmacol Ther. 2008; 27: 765-70. PubMed PMID: 18248655. DOI: 10.1111/j.13652036.2008.03630.x

26. Rittore C, Sanchez E, Soler S, Albers M, Obici L, McDermott MF et al. Grandemange SOR10-002 - A novel TNFR1 transcript of TRAPS gene. Pediatr Rheumatol Online J. 2013; 11: A186. PMCID: PMC3953180. DOI: 10.1186/1546-0096-11-S1-A186.

27. Tolusso B, Sacco S, Gremese E, La Torre G, Tomietto P, Ferraccioli GF. Relationship between the tumor necrosis factor receptor II (TNF-RII) gene polymorphism and sTNF-RII plasma levels in healthy controls and in rheumatoid arthritis. Hum Immunol. 2004; 65 (12): 1420-6. PubMed PMID: 15603867. DOI: 10.1016/j.humimm.2004.06.010.

28. Stark GL, Dickinson AM, Jackson GH, Taylor PR, Proctor SJ, Middleton PG. Tumor necrosis factor receptor type ॥ 196M/R genotype correlates with circulating soluble receptor levels innormal subjects and with graft-versus-host disease after sibling allogeneic bone marrow transplantation. Transplantation. 2003; 76: 1742-49. PubMed PMID: 14688526, DOI: 10.1097/01. TP.0000092496.05951.D5.

\section{References}

1. Lebensztejn DM, Kowalczuk D, Tarasów E, Skiba E, Kaczmarski M. Tumor necrosis factor alpha and its soluble receptors in obese children with NAFLD. Adv Med Sci. 2010; 55 (1): 74-9. PubMed PMID: 20371430. DOI: 10.2478/v10039-0100008-5.

2. Bocsan IC, Milaciu MV, Pop RM, Vesa SC, Ciumarnean L, Matei DM et al. Cytokines genotype-phenotype correlation in nonalcoholic steatohepatitis. Oxid Med Cell Longev. 2017; 2017:4297206. Epub 2017 Aug 9. PubMed PMID: 28852433. DOI: 10.1155/2017/4297206

3. Braunersreuther V, Viviani GL, Mach F, Montecucco F. Role of cytokines and chemokines in non-alcoholic fatty liver disease. World Journal of Gastroenterology. 2012; 18: 727-35. PubMed PMID: 22371632. DOI: 10.3748/wjg.v18.i8.727.

4. Lee Y-M, Sutedja DS, Wai C-T, Dan Y-Y, Aung M-O, Zhou L et al. A randomized controlled pilot study of Pentoxifylline in patients with non-alcoholic steatohepatitis (NASH). Hepatol Int. 2008; 2 (2): 196-201. PubMed PMID: 19669304. DOI: 10.1007/s12072 008-9058-1.

5. Kakino S, Ohki T, Nakayama H, Yuan X, Otabe S, Hashinaga T et al. Pivotal role of TNF- $\alpha$ in the development and progression of nonalcoholic fatty liver disease in a murine model. Horm Metab Res. 2017 Sep 18. [Epub ahead of print]. PubMed PMID: 28922680. DOI: 10.1055/s-0043-118666.

6. Locksley RM, Killeen N, Lenardo MJ. The TNF and TNF receptor superfamilies: integrating mammalian biology. Cell. 2001; 104 487-501. PubMed PMID: 11239407.

7. Cabal-Hierro L, Lazo PS. Signal transduction by tumor necrosis factor receptors. Cellular Signalling. 2012; 24: 1297-1305. PubMed PMID: 22374304. DOI: 10.1016/i.cellsig.2012.02.006.

8. DeBerge MP, Ely KH, Wright PF, Thorp EB, Enelow RI. Shedding of TNF receptor 2 by effector CD8+ T cells by ADAM17 is important for regulating TNF- $\alpha$ availability during influenza infection. JLeukocBiol. 2015; 98: 423-34. PubMed PMID: 26019295. DOI: 10.1189/jlb.3A0914-432RR.

9. Levitan BN, Astahin AV, Levitan GB. Faktor nekroza opuholej i ego rastvorimye receptory II tipa pri hronicheskih gepatitah i cirrozah pecheni. Jeksperimental'naja i klinicheskaja gastrojenterologija. 2017; 2: 62-6. Russian.
29. Crespo J, Cayón A, Fernández-Gil P, Hernández-Guerra M Mayorga M, Domínguez-Díez A et al. Gene expression of tumor necrosis factor alpha and TNF-receptors, p55 and p75, in nonalcoholic ste-atohepatitis patients. Hepatology. 2001; 34: 1158-63. PubMed PMID: 11732005.

30. Cubillas R, Kintner K, Phillips F, Karandikar NJ, Thiele DL, Brown GR. Tumor necrosis factor receptor 1 expression is upregulated in dendritic cells in patients with chronic HCV who respond to therapy. Hepat Res Treat. 2010; 2010: 429243. PMCID: PMC2989713. DOI: 10.1155/2010/429243.

31. Aderka D. The potential biological and clinical significance of the soluble tumor necrosis factor receptors. Cytokine Growth Factor Rev. 1996; 7: 231-240. PubMed PMID: 8971478

32. Till A, Rosenstiel P, Krippner-Heidenreich A, MascherettiCroucher S, Croucher PJ, Schäfer H et al. The Met196Arg variation of human TNFR2 affects TNF alpha induced apoptosis by impaired NF-kB-signalling and target gene expression. J Biol Chem. 2005; 280: 5994-6004. PubMed PMID: 15572357. DOI: 10.1074/jbc.M411541200.

33. Malhi H, Guicciardi ME, Gores GJ. Hepatocyte death: a clear and present danger. Physiol Rev. 2010; 90: 1165-1194. PubMed PMID: 20664081

34. Morita C, Horiuchi T, Tsukamoto H, Hatta N, Kikuchi Y, Arinobu Y et al. Association of tumor necrosis factor receptor type ॥ polymorphism 196R with Systemic lupus erythematosus in the Japanese: molecular and functional analysis. Arthritis Rheum. 2001; 44 (12): 2819-27. PubMed PMID: 11762942.
10. Lin SY, Wang YY, Sheu WH. Increased serum leptin concentration correlate with soluble tumour necrosis factor receptor levels in patients with cirrhosis. Clinical Endocrinol (Oxf). 2002; 57: 80511. PubMed PMID: 12460331.

11. Hui JM, Hodge A, Farrell GC, Kench JG, Kriketos A, George J. Beyond insulin resistance in NASH: TNF-alpha or adipo $\neg$ nectin? Hepatology. 2004; 40: 46-54. PubMed PMID: 15239085.

12. Tokushige K, Takakura M, Tsuchiya-Matsushita N, Taniai M, Hashimoto E, Shiratori K. Influence of TNF gene polymorphisms in Japanese patients with NASH and simple steatosis. J Hepatol. 2007; 46: 1104-10. PubMed PMID: 17395331. DOI: 10.1016/i. jhep.2007.01.028.

13. Tarrats N, Moles A, Morales A, García-Ruiz C, FernándezCheca JC, Marí M. Critical role of tumor necrosis factor receptor 1, but not 2, in hepaticstellate cell proliferation, extracellular matrix remodeling, and liver fibrogenesis. Hepatology. 2011; 54: 31927. PubMed PMID: 21523796. DOI: 10.1002/hep.24388.

14. ljiri Y, Katoa R, Sadamatsua M, Takano M, Okadac Y, Tanaka K et al. Chronological changes in circulating levels of soluble tumor necrosis factor receptors 1 and 2 in rats with carbon tetrachlorideinduced liver injury. Toxicology. 2014; 316: 55-60 PubMed PMID: 24389507. DOI: 10.1016/j.tox.2013.12.004.

15. Sorg U, Behnke K, Degrandi D, Reich M, Keitel V, Herebian D, et al. Cooperative role of lymphotoxin $b$ receptor and tumor necrosis factor receptor p55 in murine liver regeneration. Journal of Hepatology. 2016; 64: 1108-17. PubMed PMID: 26708145. DOI: 10.1016/j.jhep.2015.12.006.

16. Lana JP, Martins LB, Oliveira MC, Menezes-Garcia Z, Yamada LT, Vieira $L Q$ et al. TNF and IL-18 cytokines may regulate liver fat storage under homeostasis conditions. Appl Physiol Nutr Metab. 2016; 41: 1295-1302. PubMed PMID: 27863204. DOI: 10.1139/ apnm-2016-0265

17. Sennikov SV, Vasilyev FF, Lopatnikova JA, Shkaruba NS, Silkov AN. Polymorphisms in the tumor necrosis factor receptor genes affect the expression levels of membrane-bound type and type II receptors. Mediators Inflamm. 2014; 2014:745909. Epub 2014 Mar 24. PubMed PMID: 24782596. DOI: 10.1155/2014/745909.

18. Wang J, Ni H, Chen L, Liu YX, Chen CB, Song WQ. Preparation 
and analysis of CSNP chip on hepatocellular carcinoma-related genes. Hepatobiliary Pancreat Dis Int. 2005; 4: 398-402. PubMed PMID: 16109524.

19. Machado MV, Martins A, Almeida R, Marques-Vidal P, Gonçalves MS, Camilo ME et al. Does the simultaneous tumor necrosis factor receptor 2, tumor necrosis factor promoter gene polymorphism represent a higher risk for alcoholic liver disease? Eur J Gastroenterol Hepatol. 2009; 21: 201-5. PubMed PMID: 19212208. DOI: 10.1097/MEG.0b013e32831016e0.

20. Liu X, Invernizzi P, Lu Y. Kosoy R, Lu Y, Bianchi I et al. Genomewide meta-analyses identify three loci associated with primary biliary cirrhosis. Nat Genet. 2010; 42: 658-60. PubMed PMID: 20639880. DOI: 10.1038/ng.627.

21. Xu F, Zhou G, Han S, Yuan W, Chen S, Fu Z et al. Association of TNF- $\alpha$, TNFRSF1A and TNFRSF1B gene polymorphisms with the risk of sporadic breast cancer in northeast Chinese Han women. PloS One. 2014; 9 (7): e101138. PubMed PMID: 25010932. DOI: 10.1371/journal.pone.0101138.

22. Fletcher R. Klinicheskaja jepidemiologija. M.: Izd-vo «MediaSfera»; 1998. 352 p. Russian.

23. Glossop JR, Dawes PT, Nixon NB, Mattey DL. Polymorphism in the tumor necrosis factor receptor II gene is associated with circulating levels of soluble tumor necrosis factor receptors in rheumatoid arthritis. Arthritis Research \& Therapy. 2005; 7: 1227 34. PubMed PMID: 16277675 . DOI: 10.1186/ar1816.

24. Hunt R, Sauna ZE, Ambudkar SV, Gottesman MM, KimchiSarfaty C. Silent (synonymous) SNPs: should we care about them? Methods Mol Biol. 2009; 578: 23-39. PubMed PMID: 19768585. DOI: 10.1007/978-1-60327-411-1-2.

25. Matsukura H, Ikeda S, Yoshimura N, Takazoe M, Muramatsu M. Genetic polymorphisms of tumor necrosis factor receptor superfamily $1 \mathrm{~A}$ and $1 \mathrm{~B}$ affect responses to infliximab in Japanese patients with Crohn's disease. Aliment Pharmacol Ther. 2008; 27: 765-70. PubMed PMID: 18248655. DOI: 10.1111/j.13652036.2008.03630.x.

26. Rittore C, Sanchez E, Soler S, Albers M, Obici Let al. Grandemange SOR10-002 - A novel TNFR1 transcript of TRAPS gene. Pediatr Rheumatol Online J. 2013; 11: A186. PMCID: PMC3953180. DOI: 10.1186/1546-0096-11-S1-A186.
27. Tolusso B, Sacco S, Gremese E, La Torre G, Tomietto P, Ferraccioli GF. Relationship between the tumor necrosis factor receptor II (TNF-RII) gene polymorphism and sTNF-RII plasma levels in healthy controls and in rheumatoid arthritis. Hum Immunol. 2004; 65 (12): 1420-6. PubMed PMID: 15603867. DOI: 10.1016/j.humimm.2004.06.010.

28. Stark GL, Dickinson AM, Jackson GH, Taylor PR, Proctor SJ, Middleton PG. Tumor necrosis factor receptor type II 196M/R genotype correlates with circulating soluble receptor levels innormal subjects and with graft-versus-host disease after sibling allogeneic bone marrow transplantation. Transplantation. 2003; 76: 1742-49. PubMed PMID: 14688526. DOI: 10.1097/01. TP.0000092496.05951.D5

29. Crespo J, Cayón A, Fernández-Gil P, Hernández-Guerra M, Mayorga M, Domínguez-Díez A et al. Gene expression of tumor necrosis factor alpha and TNF-receptors, p55 and p75, in nonalcoholic ste $\neg$ atohepatitis patients. Hepatology. 2001; 34: 1158-63. PubMed PMID: 11732005

30. Cubillas $R$, Kintner $K$, Phillips F, Karandikar $\mathrm{NJ}$, Thiele DL, Brown GR. Tumor necrosis factor receptor 1 expression is upregulated in dendritic cells in patients with chronic HCV who respond to therapy. Hepat Res Treat. 2010; 2010:429243. PMCID: PMC2989713. DOI: 10.1155/2010/429243.

31. Aderka $D$. The potential biological and clinical significance of the soluble tumor necrosis factor receptors. Cytokine Growth Factor Rev. 1996; 7: 231-240. PubMed PMID: 8971478.

32. Till $A$, Rosenstiel $P$, Krippner-Heidenreich A, MascherettiCroucher S, Croucher PJ, Schäfer $\mathrm{H}$ et al. The Met196Arg variation of human TNFR2 affects TNF alpha induced apoptosis by impaired NF-kB-signalling and target gene expression. J Biol Chem. 2005; 280: 5994-6004. PubMed PMID: 15572357, DOI: 10.1074/jbc.M411541200.

33. Malhi H, Guicciardi ME, Gores GJ. Hepatocyte death: a clear and present danger. Physiol Rev. 2010; 90: 1165-1194. PubMed PMID: 20664081

34. Morita C, Horiuchi T, Tsukamoto H, Hatta N, Kikuchi $Y$, Arinobu $Y$ et al. Association of tumor necrosis factor receptor type II polymorphism 196R with Systemic lupus erythematosus in the Japanese: molecular and functional analysis. Arthritis Rheum. 2001; 44 (12): 2819-27. PubMed PMID: 11762942. 